\title{
$460 \mathrm{~kJ} / \mathrm{m}^{3}$ 磁石の開発
}

\author{
國吉 太，中原 康次，金子 裕治

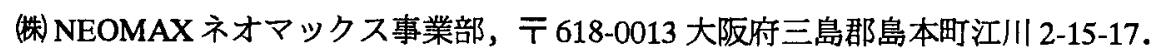

\section{Developing of $460 \mathrm{~kJ} / \mathrm{m}^{3} \mathrm{Nd}-\mathrm{Fe}-\mathrm{B}$ Magnets}

\author{
Futoshi Kuniyoshi, Koji Nakahara and Yuji Kaneko \\ NEOMAX Div., NEOMAX Co., Ltd., 2-15-17 Egawa, Shimamoto-cho, Mishima-gun, Osaka 618-0013.
}

Received May 17, 2004

\section{SYNOPSIS}

The theoretical value of the maximum energy products of the $\mathrm{Nd}_{2} \mathrm{Fe}_{14} \mathrm{~B}$ compound is calculated to be $512 \mathrm{~kJ} / \mathrm{m}^{3}$. Day and day, every researcher investigates to achieve higher maximum energy products. In order to obtain realize this theme, not only improving on alignment of the 2-14-1 grains, but also increasing the coercive force is very important. So, we have been investigating on controlling the microstructure to be fine with an excellent alignment.

As a result, we have succeeded in developing higher performance magnets having $B_{r}=1.533 \mathrm{~T}, \mathrm{H}_{\mathrm{c}}=784 \mathrm{kA} / \mathrm{m}$, (BH) $\max =460 \mathrm{~kJ} / \mathrm{m}^{3}$. New techniques to achieve at this record are as follows; (1) Reduction of impurities such as oxygen, (2) Improvement of microstructure of the strip cast alloy, (3) Development of alignment method "Inclined magnetic pulsing".

\section{KEY WORDS}

$\mathrm{Nd}-\mathrm{Fe}-\mathrm{B}$ sintered magnet, $460 \mathrm{~kJ} / \mathrm{m}^{3}$ (57.8 MGOe) magnet, new developed alloy, alignment method "inclined magnetic pulsing", reduction of impurities

\section{1 はじめに}

1982年M.Sagawaらにより発明されたNd-Fe-B系焼結磁石1) は，現在私達の生活にとって必要不可欠なものである。例え ば,ハードディスクドライブ中のVCM(ボイス・コイル・モー 夕)には、ほぼ100\% Nd-Fe-B系焼結磁石が使用され，パーソ ナルコンピュータやカーナビゲーションシステム, 最近では テレビの録画などにも用途が広がっている．また，普及の著 しい携帯電話では，高音貿のマイクロスピーカや着信を知ら せるバイブレーションモータ用にこの磁石が使われている. さらに，近年環境への関心の高まりや法規制により，各種コ ンプレッサー用モータやサーボモー夕にも本磁石は活躍の場 を広げ，省エネルギーや省スペースに一役かっている，特に 今後注目されている市場としては, ハイブリッドカー(HEV) や燃料電池車(FCEV)等の駆動用モー夕，および，発電機用で ある.自動車用途では, 過酷な環境下での使用が余儀なくさ れ, しかも, トルクアップのため高特性が要求されている.

このような市場環境の中, Nd-Fe-B 系焼結磁石の特性向上 の取り組みは, 各社, および, 各研究室でなされている。研
究室レベルでの開発において, 1987年M.Sagawaら²により初 めて $400 \mathrm{~kJ} / \mathrm{m}^{3}(50 \mathrm{MGOe})$ の壁が破られ, 2000年にはY.Kaneko $ら^{3,4)}$ が, ストリッブ・キャスティング法による急冷合金の開 発，ならびに，パルス磁界の反転印加法により， $444 \mathrm{~kJ} / \mathrm{m}^{3}$ と $55 \mathrm{MGOe}$ 以上の $(\mathrm{BH}) \max$ を有する焼結磁石か5開発された.さ らに，一昨年W.Rodewald ら うよるる微細構造制御により 451 $\mathrm{kJ} / \mathrm{m}^{3}(56.7 \mathrm{MGOe})$ に達した。

ここでは，さらなる高特性を目指し，

(1) 極限酸素量を目指した粉末製法の技術開発

(2) 急冷合金 (ストリップ・キャスト合金) 組織の最適化

(3) 成形時の粉末配向方法の最適化(新規傾斜磁場配向技術の 開発)

の課題に取り組んだ結果, $\mathrm{B}_{\mathrm{r}}=1.533 \mathrm{~T}, \mathrm{H}_{\mathrm{cl}}=784 \mathrm{kA} / \mathrm{m},(\mathrm{BH}) \mathrm{max}$ $=460 \mathrm{~kJ} / \mathrm{m}^{3}$ の磁石特性が達成できたので報告する.

\section{2 実験内容}

$\mathrm{Nd}_{125} \mathrm{~B}_{5.7} \mathrm{TM}_{0.5} \mathrm{Fe}_{\mathrm{bel}}$ ( $\mathrm{TM}=\mathrm{Al}, \mathrm{Co}, \mathrm{Cu}$ ) 組成の急冷凝固合金 ( トリップ・キャスト合金)を出発原料として, 窒素ガスジェッ 
トミル粉砕を行い，平均粒径 $3 \mu \mathrm{m}$ の微粉末を作製した.つい で，得られた微粉末をゴム型に充填し，空心コイルにてパル ス磁界で数回配向し，さらに，静水圧プレスにて成形体を得 た.ゴム型より成形体を取り出し, 1250～1363Kで焼結, 753 〜 853 K で熱処理を行った. 磁石特性は $3.2 \mathrm{MA} / \mathrm{m}$ で着磁した 後, B-Hトレーサで測定した.

\section{3 結果および考察}

\section{1 極限酸素量を目指した粉末製法}

主相比率を向上させるためには， $\mathrm{Nd}_{2} \mathrm{Fe}_{14} \mathrm{~B}$ の化学量論組成 に近づけることが有效である。しかしながら，Nd-Fe-B焼結 磁石では，液相狫結反応を進行させるために，ある一定量の $\mathrm{Nd}$ リッチ相が必要とされる.そのため,一般的に $\mathrm{Nd}_{2} \mathrm{Fe}_{14} \mathrm{~B}$ の 化学量論組成に対して,出発合金のNd量を歩増しした成分設 計を行っている(2-14-1相の化学量論組成における Nd含有量 に対して，通常 3at.\%程度の Nd を歩増しする)。

例えば，出発合金の $\mathrm{R}$ 量を 14.3 at.\% (mass production) から 12.5 at.\% (new record)にすることにより , 2-14-1相の割合を6\% 向上できると見積もれる.しかしながら，それにともない $\mathrm{R}$ リッチ相が減少するため,酸素含有量を 0.9 at.\%以下に制御で きなければ，酸化されていないRリッチ相か計算上 0 at.\%と なってしまう.すなわち，磁石化工程が進むにしたがって，大 気との接触，摩擦等による発熱でより活性な状態になり, Nd が酸化物として消費されるため, 液相焼結に必要な Ndの量が 不足してしまうのである.このような酸化によるNdリッチ相 の不足は，焼結工程においての緻密化の進行を不十分にする だけでなく，得られた焼結磁石の保磁力を低下させるため， 微粉末の酸素含有量のミニマム化は必要不可欠である.

Fig.1に新開発の潤滑剤のを使用した微粉末と,ステアリン 酸覀鉛のみを用いた微粉末の大気中での放置時間と酸素含有 量の関係を示す.ステアリン酸亜鉛のみを用いた微粉末では， 5分後には 1 at.\%を越える酸素含有量になり，さらに放置時間 とともに約 2 at.\% まで增加する．それに対して，本潤滑剤を

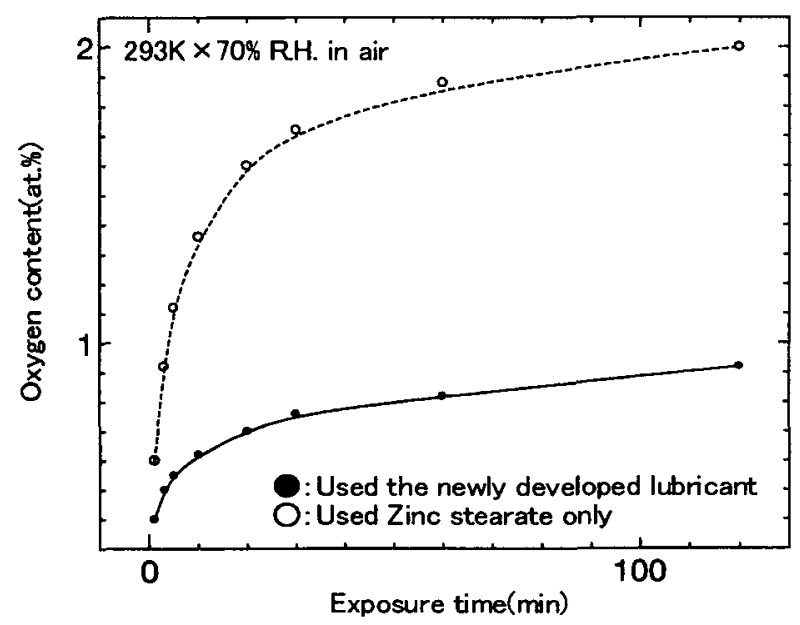

Fig.1 Dependence of oxygen content on exposure time in air.
用いて表面を被覆した微粉末では, 飛躍的に粉末の安定性(耐 酸化性) が向上し， 30 分経過しても 0.6 at.\%以下， 60 分後で も，0.9 at.\%以下の酸素含有量で抑えることができた. 今回， このような粉末の表面改質による安定性(耐酸化性)の向上に 加えて, 粉末粒度分布の最適化, 焼結条件の検討により，烤 結体の酸素含有量を 0.6 at.\%以下に抑えることが可能となり, 出発合金の成分設計をより2-14-1相の化学量論組成に近つけ て検討を進めることができるようになった。

3.2 急冷合金組織の最適化

今回，さらなる高特性化を目指すために，合金組織改善の 検討を行った》。 Nd-Fe-B系焼結磁石の高性能化のために，出 発合金としてストリップ・キャスト合金を用いることが提案 されている8-10)。一般的に用いられている R=14.3 at.\%のスト リップ・キャスト合金では，ロール面(急冷面)から放冷面に かけて, 主相結晶が成長し, Ndリッチ相が連続的に主相を取 り囲むように分散する．しかしながら，主相比率を增加させ た極低 $\mathrm{R}$ 領域の $\mathrm{Nd}=12.5$ at.\% では， $\alpha$ - $\mathrm{Fe}$ が晶出し， Nd リッ チ相が不連続になり，また，テンドライト結晶の間隔が広が り, 粗大化の傾向を示した (Fig.2(a)).

そこで，Nd=12.5 at.\%における最適な合金溶製条件を詳細 検討した結果，Fig.2(b)に示すような，Ndリッチ相が連続的 に薄く主相を取り囲み，さらに，テンドライト結晶の間隔か 狭く，急冷面から放冷面にかけて垂直にデンドライト結晶が 成長する新しい組織を有する合金を開発するに至った。これ は，ストリップ・キャスト時の冷却過程を厳密にコントロー ルすることにより, 本組成系では避けられない初晶 $\mathrm{Fe}$ を, Nd およびBの拡散により 2-14-1相を生成させ，連続的に成長さ せる.その結果, 余剩のNdはデンドライトを薄く取り囲むよ うにして欵固が完了し，このような新しい組織を有する合金 が得られたものと考えられる。

次に，微粉砕粉の粒子径と Nd 含有量との関係を Fig.3に示 す.従来製法で得られた合金では, $1 \mu \mathrm{m}$ 以下の粉末において， $\mathrm{Nd}$ 含有量が極端に高くなるのに対して，今次開発の合金で は，その偏析を半分程度に抑えることができた。これは出発 合金自体の Ndリッチ相の分散状悲が，微粉砕後にも反映さ れ，Ndリッチ相が各粒子を取り囲んだ形で粉砕が進行するた め, 成分偏析が減少する，このことが，後述の焼結性の改善 につながったと考えられる。

一般的な Nd-Fe-B焼結磁石の焼結挙動は, $938 \mathrm{~K}$ 付近の, Nd リッチ相, 主相, および, Bリッチ相の三元共晶反応, $1368 \mathrm{~K}$ 付近の主相とBリッチ相との共晶反応による液相生成により， 粒子再配列と成分抎散が容易に起こり，緻密化が進行すると されている11,12)．しかしながら，本組成系のような，低 $\mathrm{R} ・$ 低 Bな組成(主相の化学量論組成に近い組成)では，液相流動を 誘起させるための液相量が不足しがちになり，焼結が進行し にくくなることが予想される.

Fig.4に，従来溶製条件と，今次開発の合金を用いた場合の 焼結温度と密度の関係を示す.従来溶製条件の合金では1350K 付近まで焼結温度を上げないと，十分な焼結体密度が得られ 
(a) Conventional strip casting alloy

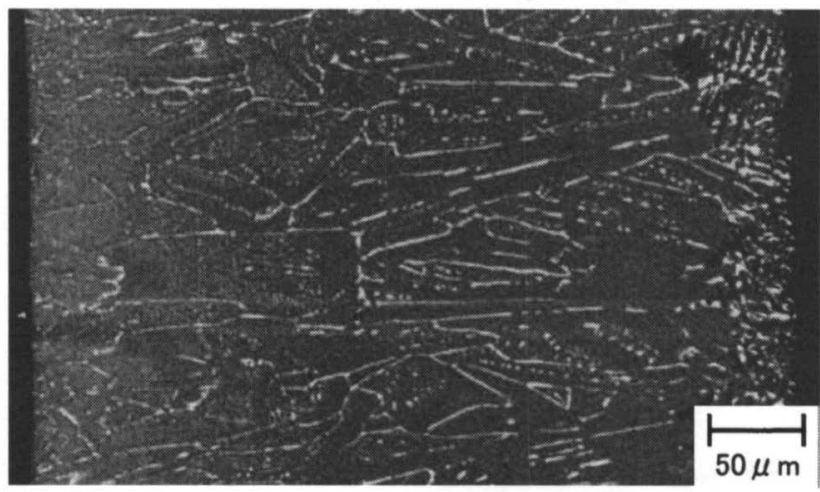

(b) Newly developed alloy

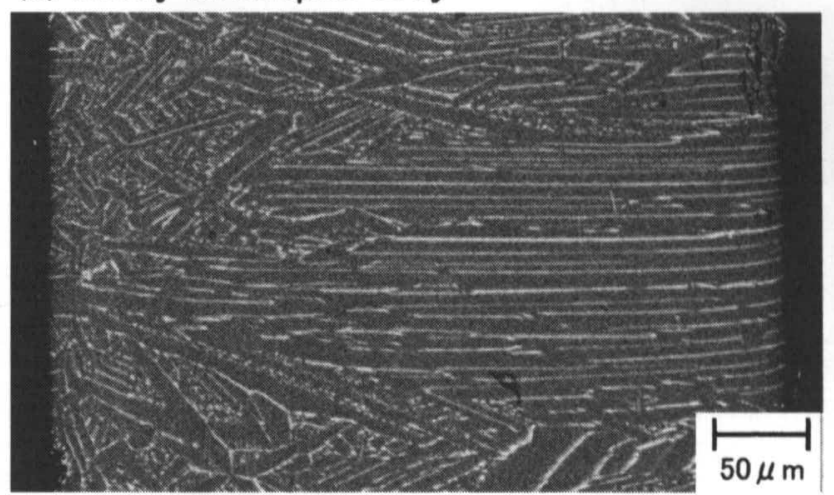

Fig.2 Backscattered electron images of Nd-Fe-B alloys prepared by (a) $\mathrm{R}=12.5$ at. $\%$ conventional strip casting. (b) $\mathrm{R}=12.5$ at.\% newly developed.

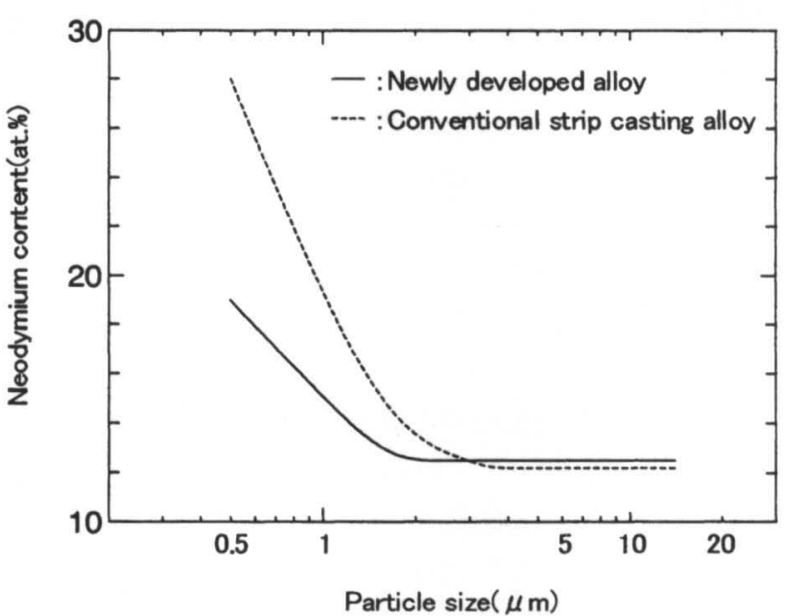

Fig.3 Relationship between particle size and neodymium content in comparison with $R=12.5$ at.\% newly developed alloy and conventional strip casting alloy.

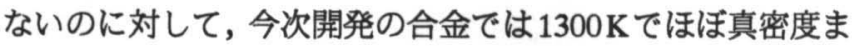
で到達することができた.これは,このような組成系では出 発合金におけるNdリッチ相の分散状態が焼結の進行に寄与す ることを示しており,合金の段階でNdリッチ相が均一に分散 することにより，焼結に有効に働いたためであると考えられ る.この焼結温度の低下により, 異常粒成長を抑えることが でき，保磁力を向上させることに成功した.

また同時に, 今次開発の合金を用いることにより， $\mathrm{B}_{\mathrm{r}}$ が向 上することがわかった．詳細は今後検討する必要があるが, 急冷面から放冷面へ垂直にデンドライト結晶が成長しており， 主相結晶の成長方向も揃っているため, 微粉砕工程を経た後 の微粉末中の結晶方向もそろいやすく, 成型時の配向, 焼結 時の配向が進行しやすい. その結果, 高保磁力, かつ高い結 晶配向を実現できる.

\section{3 成形時の粉末配向方法の最適化}

$\mathrm{Nd}-\mathrm{Fe}-\mathrm{B}$ 焼結磁石の高性能化にとって, 数 $\mu \mathrm{m}$ 程度に粉砕さ れた微粉末をいかにして同一方向へ配向させるか, また，そ

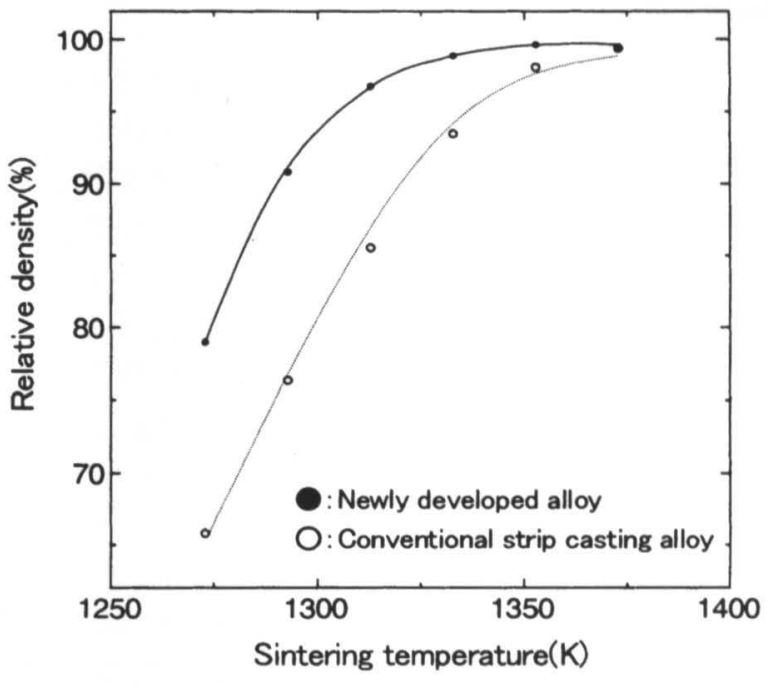

Fig.4 Relationship between sintering temperature and relative density in comparison with $\mathrm{R}=12.5$ at. \% newly developed alloy and conventional strip casting alloy.

の配向をいかにして乱さず成形するかが, 重要な技術の一つ になる.数 $\mu \mathrm{m}$ 程度に微粉砕された粉末は, クーロンカや摩擦 力等により, 加えられた磁界に対して配向を妨げる要因が存 在する. 現在までにも微粉末を高配向させる技術として様々 な検討がなされており, Kanekoらは, 原料粉末が充填された ゴム型にパルス磁界を反転印加し， CIP プロセスを用いるこ とにより，高い磁石特性が得られることを報告している ${ }^{13,14)}$.

Fig.5 に今次検討を進めた傾斜磁場配向法の模式図を示す.

原料粉末を充填したゴム型をパルス磁界により配向する場 合，既報の CIP 法において，一般的にはゴム型の中心部 (Position B) を磁界の一番高いところに配置し，原料粉末全体 に高い磁界が印加されるように設定する。これは, より高い 磁界を印加することにより配向度を改善できることによる。 また, より均一に原料粉末を配向させるために, コイルに細 工を施し，コイル中心部の磁界分布が均一になるように工夫 


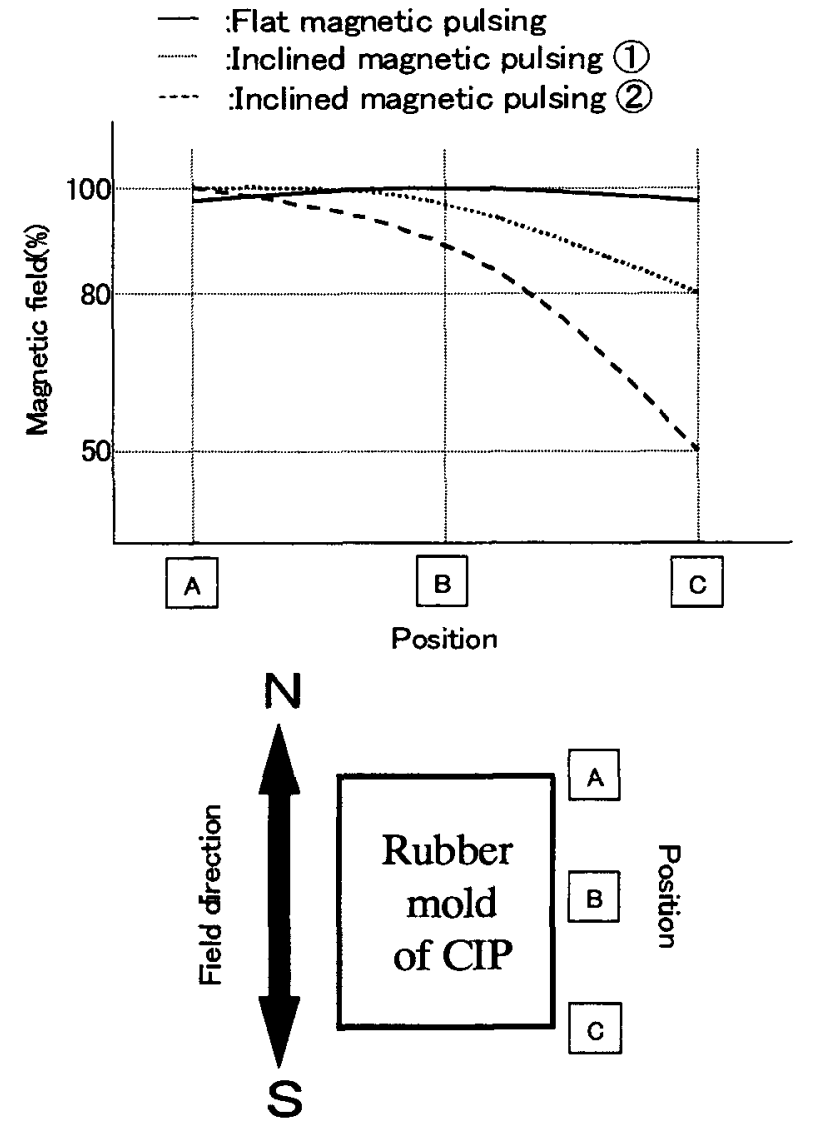

Fig.5 Schematic model of "Inclined magnetic pulsing".

する (今後本配向方法を, 均一磁場配向法 “Flat magnetic pulsing”とする). しかしながら，本報告の傾斜磁場配向法で は，ゴム型の中心部を磁界の一番高いところには配置せず， ゴム型の一端が最高磁界強度になるように配置 (Position A), もう一端はそれよりも磁界強度が弱くなるように設置し (Position C), 両端部に積極的に磁場勾配ができるようにする. このような状態で，パルス磁界を印加することにより，原料 粉末の移動と回転を起こしやすくするのである(今後本配向方 法を，傾斜磁場配向法 “Inclined magnetic pulsing”とする).

Fig.6に配向方法と磁石特性の関係を示す."Positive”は磁界 印加方向を反転させず,同じ方向に印加した場合, “Alternate” は反転印加した場合を示している．また，傾斜磁場配向法(1) (Inclined magnetic pulsing (1))は, Position Aの磁界強度を $100 \%$ とすると，もう一端の Position Cの磁界強度を $80 \%$ にして配 向したもの.傾斜磁場配向法(2)(Inclined magnetic pulsing (2)) は, Position Cの磁界強度を50\%にして配向したものである. 現在までに報告されているようにPositiveに磁界を印加するよ りも, Alternateに磁界を印加することにより $\mathrm{B}$ が向上するこ とがわかる.しかも，均一磁場配向法よりも今次開発した傾 斜碰場配向を用いる方がより効果的で，B，をさらに1\%以上向 上させることに成功した。 また，傾斜磁場配向法で配向を行 なった場合, 均一磁場配向法と比較すると, 同方向印加

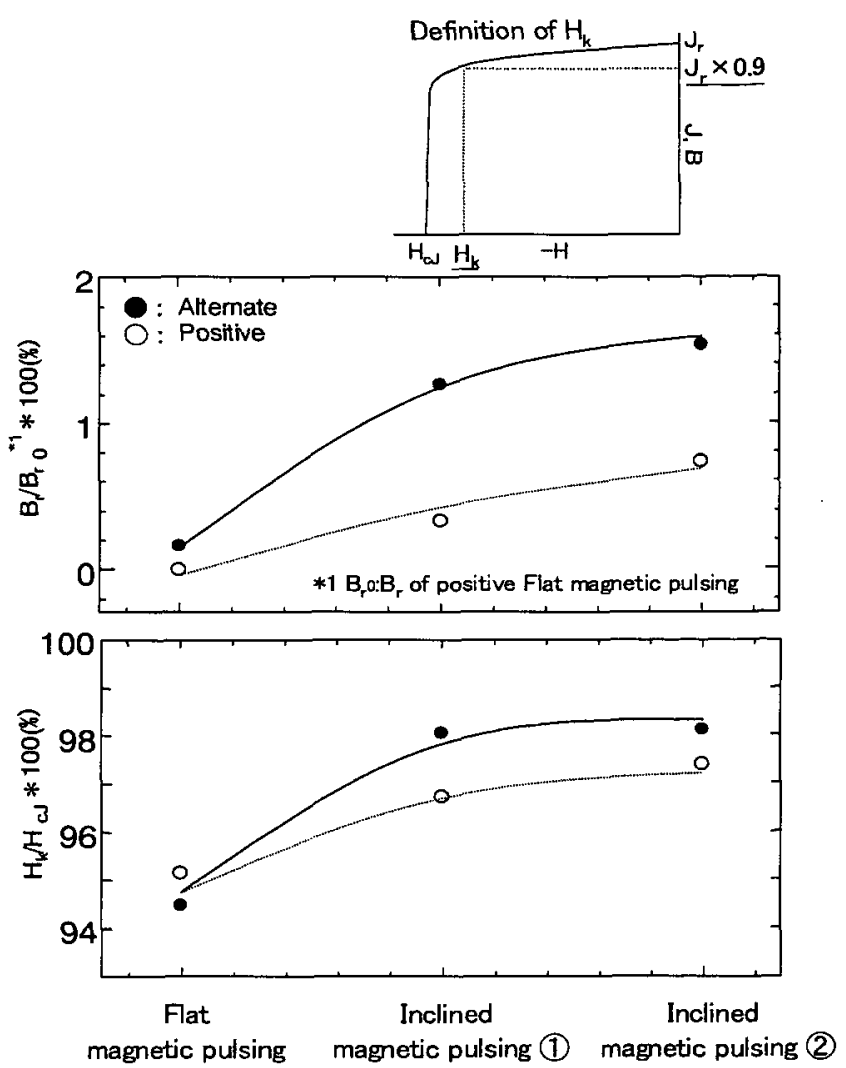

Fig.6 Effect of alignment method on $\mathrm{B}_{\mathrm{r}}$ and index of " $\mathrm{H}_{\mathrm{k}} / \mathrm{H}_{\mathrm{c}}{ }^{*} 100$ " in comparison with "Inclined magnetic pulsing" and "Flat magnetic pulsing".

(Positive) では焼結体の位圆別の $\mathrm{B}_{\mathrm{r}}$ 差が大きくなるのに対し て, 反転印加 (Alternate) では，その差が小さくなる傾向が認 められた．これは，反転印加を繰り返すことにより，より均 一に配向が進行していくためであると考えられる。

他方, 高(BH)max を達成するには減磁曲線の角形性も重要 になる．角形性の指標として $\mathrm{H}_{\mathrm{k}} / \mathrm{H}_{\mathrm{cJ}} \times 100 \%$ を用いると $\left(\mathrm{H}_{\mathrm{k}}: \mathrm{J}-\right.$ $\mathrm{H}$ 曲線の第二象限において， $\mathrm{J}_{\mathrm{r}}$ の $90 \%$ 值に該当する $\mathrm{H}_{\mathrm{c}}$ 值を $\mathrm{H}_{\mathrm{k}}$ とした), 傾斜磁場配向 +反転印加法では, 本指標の角型性が $3 \%$ 以上向上している

\section{4 世界最高級特性 $(\mathrm{BH}) \mathrm{max}=460 \mathrm{~kJ} / \mathrm{m}^{3}$ の達成}

Fig.7に今回得られた高性能磁石の隇磁特性曲線を示す. 残 留磁束密度 $\left(\mathrm{B}_{\imath}\right)$ の值は, $1.533 \mathrm{~T}$ を達成し, $\mathrm{Nd}_{2} \mathrm{Fe}_{14} \mathrm{~B}$ 金属間化 合物の飽和磁化の理論値である $1.6 \mathrm{~T} に$ 対して, 96\%の完成度 を示す.さらに，最大磁気エネルギー積 $(\mathrm{BH}) \max$ は $460 \mathrm{~kJ} / \mathrm{m}^{3}$ を記録し，保磁力 $\left(\mathrm{H}_{\mathrm{cl}}\right)$ も $784 \mathrm{kA} / \mathrm{m}$ の高い值を維持することに 成功した。

Table 1に一般的な量産材と今回得られた世界最高級材の成 分および高性能化への各因子の比較を示す，一般的な量産材 の成分は Nd=14.3 at.\%, B=6.0 at.\%であるのに対して, 今回得 られた磁石は $\mathrm{Nd}=12.5$ at.\%, B=5.7 at.\%と，より $\mathrm{Nd}_{2} \mathrm{Fe}_{14} \mathrm{~B}$ の 化学量論組成に近い設計となっている。このことにより，主 


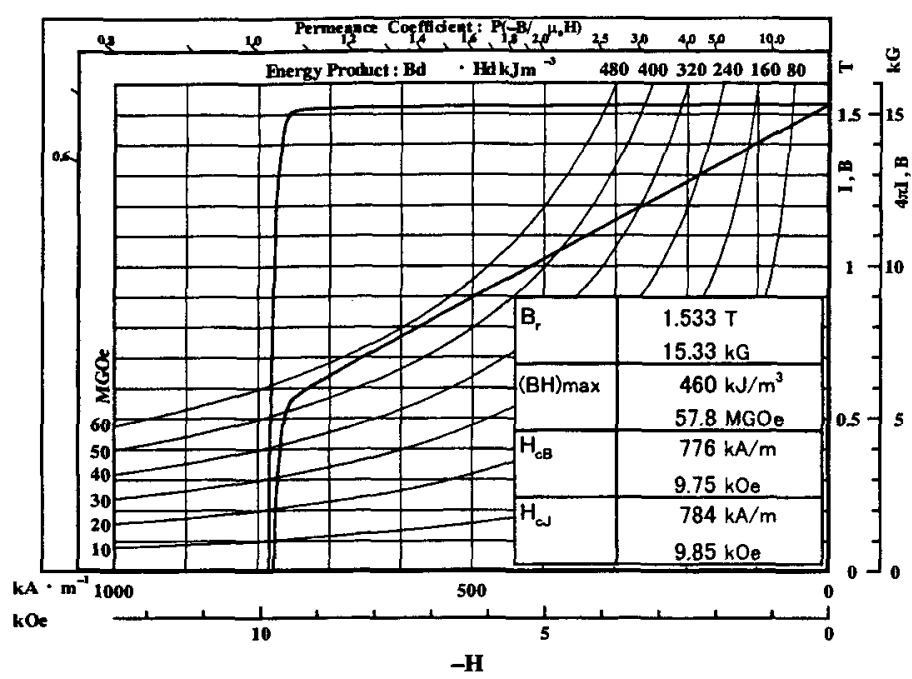

Fig.7 Demagnetization curve of Nd-Fe-B sintered magnet.

相比率を約6\%向上することができた.また, 酸素量を極限ま で低隇し，合金に改良を加えたことにより，このような成分 系でも十分に続結を進行させることに成功した．加えて，傾 斜磁場配向技術等を駆使し，配向度を $98.5 \%$ まで高めること により, $\mathrm{B}_{\mathrm{r}}=1.533 \mathrm{~T}$ を達成するに至った。

\section{5 ま と め}

$\mathrm{Nd}-\mathrm{Fe}-\mathrm{B}$ 系狫結磁石の最高特性を目指して，従来までの基 礎技術に加えて, 以下の 3 項目について研究を進めた。

(1) 極限酸素量を目指した粉末製法

(2) 急冷合金 (ストリップ・キャスト合金) 組織の最適化

(3) 成形時の粉末配向方法の最適化(新規傾斜磁場配向技術の 開発)

その結果

$\mathrm{B}_{\mathrm{r}}=1.533 \mathrm{~T}, \mathrm{H}_{\mathrm{c}}=784 \mathrm{kA} / \mathrm{m},(\mathrm{BH}) \max =460 \mathrm{~kJ} / \mathrm{m}^{3}$ の磁石特性を持

つ Nd-Fe-B 系焼結磁石を開発することに成功した。

今後は，本技術を土台とし，十分に解明されていない保磁 力についての検討を進め, さらなる高性能材 (高保磁力材)の 開発に取り組みたい。

$$
\text { 文献 }
$$

1) M.Sagawa, S.Fujimura, N.Togawa, H.Yamamoto and
Table 1 Comparison with the technical achievement of principle factors to improving magnets properties between mass production and new record.

\begin{tabular}{|c|c|c|c|c|c|c|c|}
\hline & $\begin{array}{r}\text { Compo } \\
\text { Nd }\end{array}$ & $\begin{array}{l}\text { sition } \\
\text { B }\end{array}$ & $\begin{array}{c}\text { (at..x) } \\
0\end{array}$ & $\begin{array}{c}\text { volume fraction } \\
\text { of } \\
2-14-1 \text { phase } \\
\text { \% }\end{array}$ & $\begin{array}{c}\text { degree of } \\
\text { alignment } \\
\&\end{array}$ & $\begin{array}{c}\text { sintering } \\
\text { density } \\
x\end{array}$ & \\
\hline$\frac{\text { New record }}{460 \mathrm{~kJ} / \mathrm{m}^{3}}$ & 12.5 & 5.7 & 0.6 & 97.8 & 98.5 & 99.0 & 1.53 \\
\hline $\begin{array}{l}\text { Mass production } \\
: 390 \mathrm{~kJ} / \mathrm{m}^{3}\end{array}$ & 14.3 & 6.0 & 2.0 & 92.0 & 96.5 & 99.0 & 1.41 \\
\hline
\end{tabular}

Y.Matsuura: "New material for permanent magnets on a base of Nd and Fe", J. Appl. Phys., 55(1984)2083-2087.

2) M.Sagawa, S.Hirosawa, H.Yamamoto, S.Fujimura and Y.Matsuura: "Nd-Fe-B permanent magnet materials", Jpn. J. Appl. Phys., 26(1987)785-800.

3) Y.Kaneko: "Rare-Earth magnets with High Energy Products", Proc. of $16^{\text {th }}$ Int'l. Workshop on REM \& their Applications, Japan, (2000)83.

4) Y.Kaneko, K.Tokuhara and Y.Sasakawa: "Developing and Mass-producing of Super High Performance $400 \mathrm{~kJ} / \mathrm{m}^{3} \mathrm{Nd}-\mathrm{Fe}-$ B Magnets", J. Jpn. Soc. Powder Powder Metallurgy, 47(2000) 139-145.

5) W.Rodewald, B.Wall, M.Katter, K.U" stuner and S.Steinmetz: "Extraordinary strong Nd-Fe-B magnets by a controlled microstructure", Proc. of $17^{\text {th }}$ Int'l. Workshop on REM \& their Applications, (2002)25-36.

6) Japan Patent, 3459477.

7) I.V.Belyaev, G.I.Levin and A.S.Belyshev: "Cooling rate effect on crystallization and phase composition of NdFeB type alloys", Proc. of $17^{\text {th }}$ Int'l. Workshop on REM \& their Applications, (2002)387-394.

8) Japan Patent, 2745042.

9) Japan Patent, 2665590.

10) Japan Patent, 2639609.

11) M.Matsuura, S.Hirosawa, H.Yamamoto, S.Fujimura, M.Sagawa and K.Osamura: Jpn. J. Appl. Phys., 24(1985) 10.

12) W.D.Kingery: J. Appl. Phys., 30(1959) 301.

13) Y.Kaneko: IEEE Trans. Mag., 36(2000) 3275.

14) M.Sagawa and H.Nagata: IEEE Trans. Mag., 29(1993) 2747. 